\title{
Acute respiratory coronavirus infection
}

INSERM

\section{Source}

INSERM. (1999). Orphanet: an online rare disease and orphan drug data base. Acute respiratory coronavirus infection. ORPHA:140896

Severe acute respiratory syndrome is an infectious acute pulmonary disease induced by a coronavirus. It begins with flu-like symptoms, including high fever that may be accompanied by headache and myalgies, cough, and shortness of breath. Most people with SARS subsequently develop pneumonia. 